\title{
ОСОБЕННОСТИ РЕАЛИЗАЦИИ КАТЕГОРИИ ИНФОРМАТИВНОСТИ В ЭЛЕКТРОННЫХ НАУЧНО- ПОПУЛЯРНЫХ ТЕКСТАХ С НЕВЕРБАЛЬНЫМ КОМПОНЕНТОМ
}

\section{FEATURES OF IMPLEMENTING THE INFORMATIVITY CATEGORY IN ELECTRONIC POPULAR SCIENCE TEXTS WITH A NON-VERBAL COMPONENT}

\section{N. Hristoforova}

Summary: The purpose of the research is to characterize the specifics of implementing the informativity category in an electronic popular science text, taking into account its verbal and non-verbal components. An essential feature of the research is that the analyzed text type is considered as a conversation with a non-specialist reader in order to inform him about the latest discoveries and research in the field of science and technology. The study explored both the possibilities (verbal and nonverbal) of increasing the density of information, and methods of compression within popular science discourse. The research was conducted on the material of electronic versions of the publications «Bild der Wissenschaft», "Spiegel», «Focus».

Keywords: informative content, popular science text, non-verbal component, verbal component.
Христофорова Наталья Игоревна

к.филол.н., доцент, ФГБОУ ВО «Московский авиационный институт (национальный исследовательский университет)», г. Москва

n_khristoforova@mail.ru

Аннотация: Цель исследования - охарактеризовать специфику реализации категории информативности в электронном научно-популярном тексте с учётом его вербальных и невербальных компонентов. Существенной особенностью проведенного исследования является то, что анализируемый тип текста рассматривается как беседа с читателем-неспециалистом с целью информировать его о последних открытиях и исследованиях в области науки и техники. В рамках исследования изучены как возможности (вербальные и невербальные) повышения плотности информации, так и методы компрессии в рамках научно-популярного дискурса. Исследование проведено на материале электронных вариантов изданий «Bild der Wissenschaft», «Spiegel», «Focus».

Ключевые слова: информативность, научно-популярный текст, невербальный компонент, вербальный компонент.

3. убедить адресата принять точку зрения автора на излагаемую информацию.

В связи с этим рассматриваются такие факторы сложности научно-популярного текста как информативность, соответствие нормам создания текста этого типа, авторский комментарий, стремление убедить читателя согласиться с мнением автора по поводу сообщаемой информации.

С точки зрения лингвистики научно-популярный текст можно отнести к простым текстам, поскольку он относится к речевым произведениям, содержащим единственный текст с единственным смыслом. Отметим, что автор такого текста должен стремиться к точности формулировок, исключающей множественность толкования, поскольку основное требование, предъявляемое к научно-популярному тексту - одна возможность интерпретации.

Отбор средств и методов построения научно-популярного текста производится с точки зрения соответствия основным параметрам - «высокой информативности, логичности изложения, ясности и точности 
выражения и обеспечения языкового уровня (минимальное количество терминологической лексики, описание терминов простым языком, опора на бытовое сознание читателей, их практический опыт)». [2]

Научно-популярные тексты могут передавать два типа информации, один из которых является доминирующим:

1. фактуальную информацию (отражает факты, события, которые происходили, происходят или будут происходить в действительности);

2. концептуальную информацию, предоставляющую читателю авторское понимание фактов, описанных средствами фактуальной информации.

Главной чертой такого текста является его высокая информативность, поэтому в научно-популярном дискурсе обязательно происходит «конфликт между информационной емкостью, объемностью и развернутостью высказывания и противоречащей этому требованию тенденцией к экономии языковых средств, стремлением к краткости и компактности речи, характерной для языка на современном этапе развития» [3]. Научно-популярный текст можно рассматривать как беседу автора с читателем-неспециалистом в рассматриваемой области знаний, целью которой является информирование широкого круга читателей об исследованиях, открытиях, новостях из мира науки. Для научно-популярного текста имеет значение и количественная сторона информации - информативная плотность текста, а также характерно стремление к компрессии, обусловленное общеязыковой тенденцией к экономии речевых усилий, а также задачей удерживать внимание адресата. «В своей речемыслительной деятельности человек стремится к экономии усилий. Первоочередной задачей является выбор языковых средств, при помощи которых осуществляется коммуникация». [4] Для этого задействуются научные понятия и методы, информационные ресурсы, в том числе и электронные, терминология (в небольшом количестве), могут использоваться глагольные конструкции, согласованные и несогласованные определения, предложные и беспредложные сочетания существительных с прилагательными, гнезда слов, буквенные аббревиатуры, акронимы, общепринятые и специализированные сокращения, специфические пунктуационные компрессирующие знаки, таких как скобки, диакритики, двоеточия. На синтаксическом уровне для научно-популярных текстов характерно большое количество простых распространенных предложений с обособленными оборотами, вводными словами и словосочетаниями, отражающими отношение автора к рассматриваемому предмету, эллиптических предложений - для них характерно отсутствие одного-двух главных членов, которые легко восстанавливаются из общего контекста. Названные особенности научно-популярного текста приводят к синтаксической компрессии - сокращению объема тек- ста при увеличении его информативности и смысловой наполненности.

Очевидная внутренняя форма терминов, раскрывающая их содержание, а значит, исключающая дополнительное разъяснение, превращает термины в важное средство повышения плотности информации при её изложении в самом кратком виде. Следовательно, термин - один из самых распространённых способов компрессии информации научно-популярного текста на лексическом уровне. Наиболее распространенными являются термины-композиты, такие как Linsenteleskop, Abendhimmel, Morgenstern [6].

Еще один способ компрессии в электронном научно-популярном тексте - сочетание вербальных и невербальных компонентов, таких, как фотографии, рисунки, видеофайлы, карты и др. с подписями и пояснениями. «Обработка изображений и видеоинформации занимает ведущее место в информационных процессах. В связи с ростом объемов данных возникает проблема сжатия информации, которая связана с проблемой информативности как критерия допустимого сжатия визуального образа. Термин «информационный» характеризует описательную сторону сущностей и явлений. В информационных описаниях выделяют объем и содержание. Важную роль играет именно содержание». [5] Подписи представляют собой концентрат информации, представленной в тексте, и усиливают значение невербальных средств. Включение невербальных материалов в текст бывает опосредованным - в сопровождении подписей, а также непосредственным - без сопровождения вербальных компонентов. Так, например, в тексте об исследованиях в области генетики на первой странице рубрики «Gesundheit + Medizin» приводится большое изображение компьютерной модели без подписи [7]. Изображение может привлечь внимание читателя, заставить задуматься, возможно, попытаться понять, что именно изображено, и, в итоге, открыть основной текст, где это изображение приведено уже с подписью. Благодаря своему интересу читатель получает информациюразгадку.

Опосредованное введение иллюстраций в научнопопулярный текст происходит в сопровождении подписей разного объёма: от одного предложения до текстовкомментариев или текстов-пояснений. В электронных научно-популярных текстах часто встречаются подписи в форме номинативных предложений, называющих изображение на иллюстрации. Это чаще простые двусоставные, реже, сложные предложения: в них изображение на иллюстрации называется, определяется, оценивается и разъясняется.

Например, в тексте об изучении самого древнего храма мира [8] используются фотография раскопок (вид 
сверху) с подписью: «Luftaufnahme einer der kreisförmigen Strukturen der Anlage auf dem Göbekli Тере» - «вид сверху круглой структуры», а также рисунок-схема с подписью: «Geometrische Muster lagen der architektonischen Planung eines Komplexes am Göbekli Tepe zugrunde, geht aus den Computeranalysen hervor» - «благодаря компьютерному анализу можно говорить, что в основе сооружения - геометрические расчёты».

Встречаются случаи, когда подписи представляют собой добавочное сообщение, самостоятельное по отношению к основному тексту, часто довольно ёмкое информативно. В таких случаях текст подписи может находиться рядом с иллюстрацией, открываться на отдельной странице при открытии иллюстрации в отдельном окне, заключаться в видеофайле. Так, перед основным текстом о климатических изменениях и их последствиях [9] помещена фотография реки с подписью-разъяснением:

Ein Fluss aus dem Einzugsgebiet des Ganges. Erhöhte Niederschläge in den Tropen könnten die globale Erwärmung verstärken, indem sie die Freisetzung von $\mathrm{CO} 2$ aus dem Boden verstärken. - Это река бассейна Ганга. Увеличение осадков в тропиках может усилить глобальное потепление, так как при этом усиливается выделение СО2 из почвы.

Отбирая необходимые языковые средства при написании текста, автор задает объективные параметры и степень понимания текста, в то время как адресат воспринимает этот текст субъективно. Сближению указанных позиций служит популяризация, то есть изложение содержания сложной научно-технической информации в общедоступной форме.

Создание научно-популярного текста ставит перед собой следующие цели:

1. Информирование. В тексте содержится новая для адресата информация; информативность текста для разных адресатов зависит от степени их осведомленности в рассматриваемых (и смежных с ними) вопросах. Чем более неосведомленным является читатель, тем новее для него информация.

2. Cоответствие стандартам построения научнопопулярного текста. Этот фактор определяет объективную сложность текста, обусловленную требованием однозначной интерпретации. Во избежание неверных толкований существительные не заменяются местоимениями, а повторяются столько раз, сколько необходимо, для обеспечения полноты и точности. Так, в тексте о том, для чего повреждённые кораллы изменяют окраску на яркую [10], много раз используется слово «кораллы», отдельно и в словосочетаниях. Речь идёт именно о кораллах, колониях кораллов, видах кораллов и т.д.:

Die Korallengärten der Erde sind faszinierende Naturwunder und bilden Schlüsselelemente in den komplexen
Lebensgemeinschaften der Ozeane. Baumeister der filigranen Unterwasserwelten sind Winzlinge: Die Kalkgerüste sind das Werk von Myriaden kleiner Korallenpolypen, die mit ihren feinen Ärmchen Plankton einfangen. Viele Korallenarten ernähren sich aber zusätzlich durch eine Symbiose mit Algen. Die Einzeller leben im Körper der Nesseltiere und gewinnen dort aus Sonnenlicht Energie. Von den gebildeten Kohlenstoffverbindungen geben sie den Polypen etwas ab und bekommen von ihnen im Gegenzug alles andere, was sie zum Leben brauchen.

"In gesunden Korallen wird ein Großteil des Sonnenlichts von den fotosynthetischen Pigmenten der Algensymbionten aufgenommen. Wenn die Korallen ihre Symbionten verlieren, wird das Licht jedoch zunehmend vom weißen Korallenskelett in das Gewebe der Polypen reflektiert", erklärt Wiedenmann.

3. Комментирование. Этим определяется стремление автора научно-популярного текста облегчить восприятие содержания с помощью упрощения и разъяснения трудных для понимания фрагментов, иллюстрирования примерами, рассмотрения возможных вопросов. Так, в тексте о чёрных дырах разъясняется, каким образом можно обнаружить чёрную дыру [11]:

Die meisten anderen solcher sogenannten stellaren, Stern-großen schwarzen Löcher verraten sich durch helle Röntgenstrahlung. Diese geht von der Materie aus, bevor sie in dem schwarzen Loch verschwindet. ... Stille schwarze Löcher wie das nun entdeckte verraten sich dagegen nur durch ihre Schwerkraftwirkung, etwa weil ein sichtbarer Stern sie umkreist wie in diesem Fall. - большинство этих объектов обнаруживают благодаря рентгеновскому излучению или действию силы тяжести.

В процессе изложения сложной научно-технической информации в популярной форме изложение «замедляется» - некоторые моменты рассматриваются подробнее, так осуществляется расширение определённого образа, информации рассматриваемой в тексте. Так, например, текст об археологических находках в Норвегии [12], которые стали возможны благодаря таянию ледника, разделён на: подзаголовок, вступление, разделы текста с собственными заголовками. Каждый заголовок указывает на содержание части текста:

Hufeisen, Schlittenreste und eine römische Tunika («Подкова, фрагмент саней, римская туника») - на месте, где был ледник, были найдены важные исторические свидетельства разных эпох.

Ein Bergpass für die Wikinger («Горный перевал использовали викинги»): такие маршруты - свидетельства исторических связей разных народов

Теперь можно говорить, например, о возможности внесения дополнений/изменений в историю не только Норвегии, но всего региона, а также говорить об истори- 
ческих связях и перемещениях народов этого региона.

Главная цель создания научно-популярного текста донести сложную информацию из мира науки до неспециалистов, у которых часто нет ни навыков анализа информации, ни желания его проводить, поэтому авторы избирают опорным пунктом построения текстов то, что представляет собой значимость для читателя. Понимание научно-популярного текста подразумевает «достраивание информационного содержания» и приобретение новых знаний с помощью выводов, которые способствуют совершению адресатом неречевого поступка. Этому способствуют невербальные компоненты текста - фотографии, схемы, рисунки, рисунки-реконструкции, изображения-реконструкции и другие невербальные средства.

Частой составляющей электронных научно-популярных текстов являются видеофайлы. У читателя есть возможность скачать эти видеофайлы, посмотреть их любое количество раз, увеличить изображение, остановить воспроизведение в любой момент, рассмотреть или прослушать важный, по его мнению, фрагмент, контролировать громкость воспроизведения.

Видеофайлы могут:

1) быть крайне насыщенными информативно. Так, текст статьи, рассказывающей об изучении гравитационных волн [13], состоит из одного абзаца, представляющего собой краткое изложение содержания видеофайла, а основная информация (устный комментарий/рассказ, видеоряд, подписи к нему) содержится именно в видео. Так читатель становится и зрителем:

а) он видит рассказчика/комментатора и получает информацию прямо от него;

б) читатель видит многочисленные компьютерные модели и видит в подписях, что изображено и что за исследователи внесли наибольший вклад в тот или иной этап изучения вопроса.

2) содержать дополнительную информацию, а получить её читатель может только благодаря некоторым усилиям, но он может и не захотеть их прикладывать. Так, в тексте описываются лабораторные эксперименты, в ходе которых исследователи пытаются объяснить современное состояние Марса: предположительно там происходило много вулканических извержений, на что указывают остатки лавы. Исследователи проводят аналогию с извержениями грязевых вулканов на земле [14]. Посмотрев видеофайл, читатель может представить себе, что происходило на Марсе и, возможно, на других планетах.

Кто является автором текста статьи, мы узнаём из краткой информации под/перед/слева/справа от текста. Можно перейти по ссылке и узнать больше об авторе [15]:
Справа помещена цветная фотография, рядом - гиперссылки на блоги, в создании которых участвует автop:

Florian Freistetter florian-freistetter.de www.scienceblogs.de/astrodicticum-simplex/

Ниже приводится краткая справка об авторе:

Florian Freistetter promovierte am Institut für Astronomie der Universität Wien und hat danach an der Sternwarte der Universität Jena und dem Astronomischen Rechen-Institut in Heidelberg als Astronom gearbeitet. Zur Zeit lebt er in Jena, bloggt über Wissenschaft und schreibt manchmal Bücher.

Отметим, что справа дано много информации об авторе статей:

- помещён рисунок - цветное изображение автора,

- под рисунком - такая же информация, что и перед списком его статей в данном издании, с дополнением:

Florian Freistetter promovierte am Institut für Astronomie der Universität Wien und hat danach an der Sternwarte der Universität Jena und dem Astronomischen Rechen-Institut in Heidelberg als Astronom gearbeitet. Zur Zeit lebt er in Baden bei Wien, bloggt über Wissenschaft, schreibt Bücher und ist Teil des Wissenschaftskabaretts Science Busters. - автор состоит в научном сообществе австрийских учёных (на него приводится гиперссылка).

Далее размещены обложки книг, написанных исследователем (оснащены гиперссылками), гиперссылки на блог автора, дополнительную информацию по астрономии и др.

Иногда рядом с текстом (перед ним) помещается информация об авторе. Так, например, информациясправка об авторе ряда статей [16] помещена перед ними. Справка содержит цветную фотографию автора, смотрящего на читателя, и это помогает «установить контакт» автора и читателя, повысить доверие к информации в последующих статьях. Обязательно указывается сфера профессиональных интересов автора, напримep:

Kurt Stukenberg (выделение жирным шрифтом, большего размера, чем текст информации об авторе)

Jahrgang 1988. War bis Juni 2018 Chefredakteur des Greenpeace Magazins in Hamburg. Zuvor arbeitete er dort mehrere Jahre als Redakteur und Leiter Digital-Strategie. Seit November 2018 stellvertretender Ressortleiter Wissenschaft beim SPIEGEL.

Научно-популярный электронный текст содержит гиперссылки, дающие читателю возможность получить дополнительную информацию:

1) Quelle: Eidgenössische Technische Hochschule Zürich, Fachartikel: Science, doi: 10.1126/science.aau7187 
[7] - указание на статью со специализированного сайта, в которой содержатся результаты исследований, то есть текст первичной информативности, на основе которого был написан рассматриваемый научно-популярный текст.

2) «Zum Thema», «Mehr zum Thema» и др. - перейдя по этой ссылке можно прочитать другие статьи той же тематики, опубликованные в том же издании.

На основании проведённого исследования можно утверждать, что в электронном научно-популярном тексте категория информативности является одной из основных, ведь этот тип текста характеризуется целью проинформировать читателя-неспециалиста о последних событиях из мира науки и техники. Автор использует все возможности предоставления читателю информации, как в плане вербальном, так и в плане невербальном, стараясь максимально проинформировать читателя, помочь ему понять суть открытия (исследования), оценить важность предложенной информации и, возможно, вызвать у него желание обменяться этой информацией с кем-либо.

\section{ЛИТЕРАТУРА}

1. Голубева Т.И. Связь темпоральной структуры произведений мемуарного жанра с видами информации и композиционно-речевыми формами изложения (на материале дневников и воспоминаний)//Филологические науки. Вопросы теории и практики. Тамбов: Грамота, 2017. № 8(74): в 2-х ч. Ч. 2. C. $99-102$.

2. Зорина Ю.В. К вопросу о некоторых специфических чертах научного дискурса//Международный научно-исследовательский журнал. Екатеринбург. Издво: Соколова Марина Владимировна, 2018. № 8(74). С. 128-131

3. Гудухина М.Н. Особенности использования предикативных структур в англоязычных научных текстах//Вестник МГлу. Гуманитарные науки. Москва. Изд-во: МГЛУ, 2018. № 18(816). С. 86-97

4. Бредихин С.Н., Серебрякова С.В., Лиховид А.А. Способы компрессии когнитивной информации в научно-популярном тексте//Актуальные проблемы филологии и педагогической лингвистики. Владикавказ. Изд-во: Северо-Осетинский гос. пед. ун-т им. К.Л. Хетагурова, 2019. № 3. С. 139-145

5. Номоконов И.Б. Визуальная информативность//ИТНОУ: Информационные технологии в науке, образовании и управлении. Москва. Изд-во: 000 «Институт новых информационных технологий», 2019. № 3 (13). С. 66-72

6. Alderamin. Beobachtungstipp: Merkur und Venussichel im Feldstecher. Bild der Wissenschaft/ScienceBlogs. 2020 [электронный pecypc] URL: http://scienceblogs. de/alpha-cephei/2020/05/24/beobachtungstipp-venussichel-und-merkur-im-feldstecher/ (дата обращения: 24.05.2020)

7. Vieweg, Martin. Elektronische Genregulation. Bild der Wissenschaft. 2020 [электронный ресурc] URL: https://www.wissenschaft.de/gesundheit-medizin/ elektronische-genregulation/ (дата обращения: 29.05.2020)

8. Vieweg, Martin. Neues vom ältesten Tempel der Welt. Bild der Wissenschaft. 2020 [электронный ресурс] URL: https://www.wissenschaft.de/geschichtearchaeologie/neues-vom-aeltesten-tempel-der-welt/ (дата обращения: 14.05.2020)

9. Vieweg, Martin. Klimawandel: Nasse Selbstverstärkung. Bild der Wissenschaft. 2020 [электронный ресурc] URL: https://www.wissenschaft.de/erde-klima/ klimawandel-nasse-selbstverstaerkung/(дата обращения: 06.05 .2020 г.)

10. Vieweg, Martin. Farbintensiver Überlebenskampf. Bild der Wissenschaft. 2020 [электронный ресурc] URL:_https://www.wissenschaft.de/umwelt-natur/ farbintensiver-ueberlebenskampf/(дата обращения: 25.05.2020)

11. koe/dpa. Neu entdecktes schwarzes Loch ist unserer Erde am nächsten. Der Spiegel. 2020 [электронный ресурс] . URL:https://www.spiegel.de/wissenschaft/ weltall/schwarzes-loch-forscher-entdecken-erdnaechstes-schwerkraftmonster-a-8105сc26-7ce2-48af-9dda-223bc0f3d968_(дата 06ращения: 06.05.2020)

12. Podbregar, Nadja. Gletscherrückgang enthüllt Bergpass der Wikinger. Bild der Wissenschaft. 2020 [электронный ресурс] URL: https://www.wissenschaft.de/ geschichte-archaeologie/gletscherrueckgang-enthuellt-bergpass-der-wikinger/ (дата обращения: 19.05.2020)

13. Clixoom Science \& Fiction. Neue Ära der Gravitationswellenforschung: Brummende Art entdeckt. FOCUS. 2020. [электронный pecypc] URL: https://www.focus. de/wissen/weltraum/neuartige-gravitationswellen-aufgespuert-neue-aera-der-gravitationswellenforschung-brummende-art-entdeckt_id_12030175.html (дата обращения: 26.05.2020)

14. Vieweg, Martin. Mars: Spuren von Schlammvulkanismus? Bild der Wissenschaft. 2020 [электронный ресурc] URL: https://www.wissenschaft.de/astronomiephysik/mars-spuren-von-schlammvulkanismus/ (дата обращения: 18.05.2020)

15. Freistetter, Florian. Рубрика Astrodicticum Simplex. Bild der Wissenschaft/ScienceBlogs. 2020 [электронный ресурc] URL: http://scienceblogs.de/astrodicticumsimplex/author/ffreistetter/(дата обращения: 31.05.2020)

16. Kurt Stukenberg. Autor. Der Spiegel. 2020 [электронный ресурc]. URL: https://www.spiegel.de/impressum/autor-4affdf21-0001-0003-0000000000026468(дата обращения: 30.05 .2020 г.)

(c) Христофорова Наталья Игоревна (n_khristoforova@mail.ru).

Журнал «Современная наука: актуальные проблемы теории и практики» 